Canadian Journal of Fisheries and Aquatic Sciences

Canadian

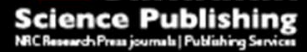

Journal canadien des sciences halieutiques et aquatiques

\title{
Trophic roles determine coral reef fish community size structure
}

\begin{tabular}{|r|l|}
\hline Journal: & Canadian Journal of Fisheries and Aquatic Sciences \\
\hline Manuscript ID & cjfas-2015-0178.R2 \\
\hline Manuscript Type: & Article \\
\hline Date Submitted by the Author: & $17-$ Dec-2015 \\
\hline Complete List of Authors: & $\begin{array}{l}\text { Robinson, James; University of Victoria, Biology } \\
\text { Baum, Julia; University of Victoria, Department of Biology }\end{array}$ \\
\hline & $\begin{array}{l}\text { ABUNDANCE < General, FISHES < Organisms, CORAL REEFS }< \\
\text { Environment/Habitat, ECOLOGY < General, TROPHIC RELATIONSHIPS < } \\
\text { General }\end{array}$ \\
\hline
\end{tabular}

\section{SCHOLARONEm}

Manuscripts 


\section{Trophic roles determine coral reef fish community size structure}

2

James P.W. Robinson ${ }^{1}$, Julia K. Baum ${ }^{* 2}$

4

1 Department of Biology, University of Victoria, PO BOX 1700 Station CSC, Victoria

6 British Columbia, V8W 2Y2, Canada; Email: jamespwr@uvic.ca

2 Department of Biology, University of Victoria, PO BOX 1700 Station CSC, Victoria

8 British Columbia, V8W 2Y2, Canada; Email: baum@uvic.ca Fax: 250-721-7120

*Corresponding Author

10

12

14

16

18

20

22

24

26

28 


\section{Abstract}

32 Relationships between abundance $\sim$ body size and trophic position $\sim$ body size can reveal size structuring in food webs, and test ecological theory. Although there is considerable

34 evidence of size structuring in temperate aquatic food webs, little is known about the structure of tropical coral reef food webs. Here, we use underwater visual census data and

36 nitrogen stable isotope analysis to test if coral reef fish communities are 1) size structured and 2) follow metabolic scaling rules. Examining individuals from over 160 species

38 spanning four orders of magnitude in body size, we show that abundance scaled negatively with body size and, as predicted, individuals sharing energy through predation

40 (carnivorous fishes) scaled more steeply than those individuals sharing a common energy source (herbivorous fishes). Estimated size spectra were, however, shallower than

42 predicted by metabolic theory. Trophic position scaled positively with body size across species and across individuals, providing novel evidence of size structuring in a diverse

44 tropical food web. Size-based approaches hold great promise for integrating the complexities of food webs into simple quantitative measures, thus providing new insights

46 into the structure and function of aquatic ecosystems.

48 Keywords: Body size; size spectrum; metabolic theory; herbivory; stable isotopes 


\section{Introduction}

Elucidating the structure of natural food webs can provide fundamental insight

56 into ecosystem dynamics, including energy fluxes (Lindeman 1942; Rooney et al. 2008), trophic cascades (Bascompte et al. 2005; Tunney et al. 2012), and potentially the

58 mechanisms underlying ecosystem stability (May 1973; Rooney \& McCann 2012). General patterns relating to body size may be of particular importance since individual 60 metabolic rates, and thus many important biological processes, vary consistently with body size (Peters 1983; Brown et al. 2004). In size-structured food webs, predators are

62 typically larger than their prey (Elton 1927; Brose et al. 2006) and abundance is predicted to scale with body size due to energetic constraints (Brown \& Gillooly 2003).

64 Specifically, when individuals share a common energy source abundance is predicted to scale with body mass $(\mathrm{M})$ as $\sim \mathrm{M}^{-3 / 4}$ (the energetic equivalence hypothesis) (Brown \&

66 Gillooly 2003), whereas when individuals compete for energy through predation at multiple trophic levels, abundance is further constrained by inefficient energy transfer

68 across trophic levels and predicted to scale as $\sim \mathrm{M}^{-1}$ (trophic transfer correction) when the predator-prey mass ratio is $10^{4}$ and transfer efficiency is $10 \%$ (Jennings \& Mackinson

70 2003; Trebilco et al. 2013).

Size structuring in aquatic food webs is driven by two mechanisms that reflect

72 size-based feeding amongst individuals: first, gape limitation restricts the size of prey that many aquatic species can consume (Brose et al. 2006; Barnes et al. 2010), and second,

74 ontogenetic diet shifts often lead to increases in trophic position as individuals grow (Mittelbach \& Persson 1998). As a result, trophic position is often positively related to 76 body size in aquatic food webs both at the species (Brose et al. 2006) and individual level 
(Jennings et al. 2001). Size structuring of abundance and individual trophic position has

78 been clearly demonstrated in both temperate freshwater (Mittelbach \& Persson 1998, Cohen et al. 2003) and marine food webs (Jennings et al. 2001; Jennings \& Mackinson

80 2003). Similarly, metabolic scaling predictions (Brown \& Gillooly 2003) have been broadly validated in freshwater (Reuman et al. 2008) and marine food webs (Jennings \&

82 Mackinson 2003). However, equivalent tests of size structuring in tropical systems are few, and tests of metabolic predictions are lacking entirely. One study of a tropical

84 riverine food web, which found that trophic position was unrelated to body size despite a significant positive correlation between mean predator body size and prey size (Layman

86 et al. 2005), concluded that the broad range of primary consumer body sizes in their system accounted for this difference from the structure of temperate food webs. However,

88 community-wide analyses of tropical size structure remain relatively unexplored.

On tropical coral reefs, the application of sized-based approaches has been

90 restricted to observations of body size distributions in degraded regions or to diet analyses of individual species. For example, size spectra - a widely used form of

92 individual abundance - body size relationship - have been used to describe reef fish community structure along gradients of fishing effort (Dulvy et al. 2004; Wilson et al.

94 2010) and habitat complexity (Alvarez-Filip et al. 2011). Though consistent with sizestructured abundances, size spectra have typically been fitted to narrow body size ranges

$96(\sim 10-60 \mathrm{~cm})$ and used to detect community change rather than to delineate trophic structure. Similarly, tests of ontogenetic diet shifts often focus on intraspecific

98 relationships for single or few species (Greenwood et al. 2010; Plass-Johnson et al. 2012; 
Hilting et al. 2013) and thus fail to examine size-based relationships at the community 100 level.

Attempts to infer food web structure through body size relationships should also

102 account for distinct feeding strategies within the same community size spectrum. Metabolic theory predicts that abundance - body size relationships are dependent on how

104 energy is utilised within a community (Brown \& Gillooly 2003). For example, in the North Sea food web, the size spectrum of the benthic community that feeds on a shared

106 energy source is shallower than the predation-based pelagic community size spectrum (Maxwell \& Jennings 2006; Blanchard et al. 2009). Distinct trophic pathways also are 108 expected in coral reef ecosystems where, specifically, herbivorous and detritivorous fishes share benthic material (Dromard et al. 2015) while planktivorous fishes derive 110 energy from pelagic sources (Wyatt et al. 2012). Small to medium-sized mesopredator fishes feed on reef fish and invertebrate species, thus accessing benthic and pelagic

112 energy sources within the reef habitat and competing across trophic levels (Rogers et al 2014), while large predatory reef fish may forage more widely than mesopredators and

114 couple pelagic open-ocean and benthic reef habitats (McCauley et al. 2012; Frisch et al. 2014). By considering size-based patterns within the distinct trophic pathways of

116 herbivores and carnivores we can examine food web structure in the context of metabolic predictions.

118 Here, we capitalize on the opportunity to sample a minimally impacted coral reef in order to empirically test the hypotheses that coral reef food webs are size structured

120 and fit predictions from metabolic theory. We combine visual census data with stable isotope samples from Kiritimati, a remote atoll in the central equatorial Pacific, to 
122 examine the food web structure of a diverse tropical fish community spanning four orders of magnitude in body mass. We expected negative abundance - body size relationships

124 and positive trophic position - body size relationships, consistent with size structuring. We also expected steeper body size relationships for both trophic position and abundance

126 in a predation-based community (carnivores) relative to an energy-sharing community (herbivores).

\section{Materials and methods}

\section{Study site and data collection}

We examined a minimally disturbed coral reef fish community on Kiritimati

132 (Christmas Island) in the equatorial Pacific Ocean (Fig. 1). Kiritimati supports a population of at least 5500 people that is concentrated around several villages on the

134 northwest coast (Kiribati National Statistics Office 2012). Subsistence fishing is the primary human impact on the atoll, and has been associated with decreases in reef fish

136 biomass and top predator abundance (Sandin et al. 2008). Fishing activities are, however, mostly concentrated around the villages on the northwest coast, whereas the reefs on the

138 north, east, and south coasts are relatively undisturbed (Walsh 2011; M. Watson, D. Claar, J. Baum, unpublished data). The northwest coast of Kiritimati is also subject to 140 oceanic upwelling of nutrients, but industrial and agricultural nutrient run-off is virtually non-existent around the atoll (Walsh 2011). We enumerated and sampled coral reef fishes

142 at fourteen minimally disturbed sites on Kiritimati's north and east coasts (Fig. 1), in order to reduce potentially confounding effects of fishing and nutrient inputs on trophic 144 structure (Post 2002). 
To quantify coral reef fish community structure, fish abundance and size data 146 were recorded during SCUBA underwater visual censuses (UVC) at shallow forereef sites $(\mathrm{n}=14,10-12 \mathrm{~m}$ depth) around Kiritimati in July and August of 2011 and 2013 (Fig.

148 1). During each census, two experienced scientific divers identified, counted and sized (total length, to the nearest $\mathrm{cm}$ ) reef fishes by swimming in tandem along $25 \mathrm{~m}$ long belt

150 transects whose bearings were determined haphazardly such that they remained within the 10-12 m depth isobath. On each transect, fishes $\geq 20 \mathrm{~cm}$ total length were counted

152 along the transect in an $8 \mathrm{~m}$ wide strip, before counting fishes $<20 \mathrm{~cm}$ total length along the reverse direction in a $4 \mathrm{~m}$ wide strip. Three transects, each separated by $10 \mathrm{~m}$, were

154 surveyed at each site during each UVC such that the total area surveyed per UVC was $600 \mathrm{~m}^{2}$ (i.e. 3 X $25 \times 8 \mathrm{~m}$ ) for large fishes and $300 \mathrm{~m}^{2}$ for small fishes. Before analyzing

156 the UVC data, we standardized the sampling area by doubling all counts of the small fishes $(<20 \mathrm{~cm})$ for each transect. Each site was surveyed once in 2011 and twice in

158 2013, all during daylight hours. All surveys were conducted by only four divers, with a single diver participating in every survey. To reduce observation error, for two days on

160 Kiritimati immediately before beginning visual censuses, each diver refamiliarized themselves with fish species identification as well as with underwater size estimation,

162 using PVC objects of fixed sizes (Bell et al. 1985); divers typically could estimate fish lengths with minimal error (e.g. $\pm 3 \%$ ). Fish length estimates were converted to body

164 mass (grams) using published species-specific length-weight relationships (Kulbicki et al. 2005; Froese and Pauly 2012).

166 To quantify coral reef trophic structure, we collected specimens of the most abundant fish species on Kiritimati (as determined by UVCs conducted in 2007 (Walsh 
168 2011) and 2009) for each of the five major putative functional groups (described below; Table 1). For each species, we aimed to collect individuals spanning the entire species'

170 body size range, with a minimum of three individuals in each $\log _{2}$ mass bin. In JulyAugust of 2011 and 2012, divers captured fish using a combination of custom built

172 microspears, pole spears, and spear guns at shallow forereef sites ( $\mathrm{n}=10,8-12 \mathrm{~m}$ depth). Fish were captured opportunistically, and the number of specimens per site varied from 6

174 to $79($ mean $=34)$. Specimens were immediately put on ice until dissection later that evening (typically $\sim 4-8$ hours between collection and dissection). Prior to dissection,

176 each individual was photographed, weighed, and measured to the nearest millimeter with vernier calipers (for standard, fork, and total length). We then excised a small sample

$178(\sim 10 \mathrm{~g})$ of dorso-lateral white muscle tissue from each fish before freezing at $-20^{\circ} \mathrm{C}$. Samples were kept frozen with dry ice for transport from Kiritimati to the University of

180 Victoria and then stored at $-20^{\circ} \mathrm{C}$ until processing.

Each white muscle tissue sample was rinsed with de-ionized water, dried at $60^{\circ} \mathrm{C}$

182 for 48 hours, and ground to a powder with a mortar and pestle. Tissue samples were weighed to $10 \mathrm{mg}$ and placed into a tin capsule before analysis of nitrogen stable isotope

184 concentrations at the Mazumder laboratory (Department of Biology, University of Victoria, BC, Canada). Relative nitrogen content was estimated by continuous flow

186 isotope ratio mass spectrometer and reported in parts per million relative to atmospheric $\mathrm{N}^{2}\left(\delta^{15} \mathrm{~N}\right)$.

\section{Coral reef fish functional groups and trophic pathways}

We assigned each fish species recorded in our underwater visual censuses to one 190 of five functional groups distinguished by their diet preferences following Deith (2014) 
(Table 1). We note that species within the 'herbivore' functional group can feed on both 192 plant material and detritus. Gut content analyses of our specimens were used to confirm the functional group of each species.

To account for differences in energy acquisition within the fish community, we aggregated our visual census and isotope data into two groups, carnivores and herbivores

196 (Table 1). We hypothesized that planktivores, benthic invertivores, corallivores and piscivores compete for energy in a group that is structured by predation (as in Rogers et

198 al. 2014), whereas herbivorous and detritivorous species compete for a shared energy source of plant material and detritus in a separate herbivore group (Choat 1991). In our

200 UVC data, nine species were classed as omnivores (Deith 2014). Because omnivores feed on both plant and animal material, these species did not fit into either trophic pathway

202 and so were omitted from all analyses. Omnivores comprised only $8.4 \%$ of the numerical abundance of fishes in our UVC surveys, and their inclusion as either herbivores or

204 carnivores did not qualitatively change our results (see Supplementary Material).

\section{Abundance - body size analyses}

In aquatic systems, the relationship between individual abundance and body size

(or size spectrum) has typically been estimated on a logarithmic scale as the slope of the

208 linear regression fit to abundance data binned into body size classes (e.g. Jennings et al. 2001; Jennings \& Mackinson 2003). However, recent studies have recognized that, rather

210 than forming a bivariate relationship, these types of data follow a frequency distribution (i.e. of the number of individuals at each size), and that binning-based methods yield

212 biased slope estimates (Edwards 2008; White et al. 2008). As such, we examined the size structure of fish abundances by fitting the visual census body mass data to a bounded 
214 power law distribution (Equation 1):

$$
(b+1)\left(x_{\max }^{b+1}-x_{\min }^{b+1}\right)^{-1} x^{b}
$$

216 where $\mathrm{x}_{\min }$ and $\mathrm{x}_{\max }$ are the minimum and maximum observed body masses, respectively, and the exponent $b$ describes the relative abundance of different body sizes (Edwards et

218 al. 2012). We used maximum likelihood methods to estimate $b$ with $95 \%$ confidence limits (White et al. 2008). Interpretations of how empirical size spectra relate to theoretical metabolic predictions can be confounded by the method used to estimate the slope. Here, we explain how our estimates of $b$ relate to Brown \& Gillooly's (2003) theoretical predictions and to the empirical estimates of others. First, our maximum likelihood

224 approach treats untransformed body size data as a continuous variable, whereas metabolic theory describes abundance - body mass relationships across logarithmic size bins

226 (Brown et al. 2004). As outlined by Reuman et al. (2008), this implies that Brown \& Gillooly's (2003) predicted slopes will be one unit shallower than the scaling exponent of 228 a power law distribution (Andersen \& Beyer 2006). That is, the predicted abundance body mass scaling exponents are $b=-1.75$ under the energetic equivalence hypothesis 230 and $b=-2$ with the trophic transfer correction (Trebilco et al. 2013), rather than -0.75 and -1 respectively. Second, size spectra slopes are typically estimated empirically using a

232 simple logarithmic binning method that also estimates a shallower slope. Here, $b+1$ is analogous to a size spectrum slope estimated with a regression of numerical abundance

234 against the midpoints of size bins on a log-log scale (Reuman et al. 2008; White et al. 2008), but is an unbiased estimate of the relationship. Thus, previous empirical tests of theoretical predictions (e.g. Jennings \& Mackinson 2003; Blanchard et al. 2009) can also 
simply be corrected (true $b=$ slope -1 ) to serve as a useful guideline for interpreting the 238 slopes of our community size spectra.

Here, all observed body masses $>1 \mathrm{~g}$ were summed across visual census sites to

240 fit the size spectrum of 1) the full reef fish community and 2) each putative trophic pathway (carnivores and herbivores). We tested the robustness of our results several

242 ways. First, we examined the potential influences of year and observer by fitting separate size spectra for each year $(2011,2013)$ and for each dive team $(n=3)$. Second, although

244 our survey sites were selected in order to minimize fishing effects on reef trophic structure, we recognize that sites on Kiritimati's north coast may experience light fishing

246 pressure. To test for potential fishing effects we removed north coast sites that are nearest to Kiritimati's population centres and refitted spectra, and also compared size spectra for 248 north vs. east coast sites (Supplementary Material). Third, we tested the effect of fitting different body size ranges on exponent estimates, thus excluding either the smallest fishes

250 (because our UVCs may have undersampled them) or the largest fishes (because these may be targeted by fishers) (Supplementary Material).

\section{Trophic position estimation}

We assigned all fish specimens to $\log _{2}$ mass bins (grams) and converted the $\delta^{15} \mathrm{~N}$

254 values of each individual to trophic position. $\delta^{15} \mathrm{~N}$ of an organism's tissue reflects its diet and, given that $\delta^{15} \mathrm{~N}$ increases by a known discrimination factor $\left(\Delta^{15} \mathrm{~N}\right)$ between predator

256 and prey, $\delta^{15} \mathrm{~N}$ can be used as a proxy for trophic position (Post 2002). $\Delta^{15} \mathrm{~N}$ is commonly set at 3.4\%o, though recent work has revealed that $\Delta^{15} \mathrm{~N}$ decreases with the $\delta^{15} \mathrm{~N}$ of an

258 organism's diet such that upper trophic positions may previously have been underestimated (Caut et al. 2009; Hussey et al. 2014). 
method, which accounts for variation in $\Delta \Delta^{15} \mathrm{~N}$ due to dietary $\delta^{15} \mathrm{~N}$ (Equation 2):

$262 \quad(2)$

$$
T P_{\text {scaled }}=T P_{\text {base }}+\frac{\log \left(\delta^{15} N_{\text {lim }}-\delta^{15} N_{\text {base }}\right)-\log \left(\delta^{15} N_{\text {lim }}-\delta^{15} N_{\text {fish }}\right)}{k}
$$

This method was developed in a meta-analysis of experimental isotope studies of marine

264 and freshwater fishes, where $\delta^{15} N_{\text {lim }}(21.926)$ and $k(0.315)$ are derived from the intercept and slope of the relationship between $\Delta \mathrm{N}$ and dietary $\delta^{15} \mathrm{~N}$ (Hussey et al. 2014). Trophic

266 position (TP) was estimated relative to the $\delta^{15} \mathrm{~N}$ of a baseline organism, where $\mathrm{TP}_{\text {base }}$ was set to 3 and $\delta^{15} \mathrm{~N}_{\text {base }}$ was the mean $\delta^{15} \mathrm{~N}$ of the smallest planktivore species we sampled on 268 Kiritimati (Chromis vanderbilti, $\delta^{15} \mathrm{~N}_{\text {base }}=10.26$, mass $=0.1 \mathrm{~g}$ ).

Herbivores are known to fractionate differently than carnivores, with recorded

$270 \Delta \Delta^{15} \mathrm{~N}$ values ranging from $-0.7 \%$ to $9.2 \%$ (Vander Zanden \& Rasmussen 2001). In herbivorous reef fish, substantially higher feeding and excretion rates are required to 272 subsist on low energy algal food sources, driving higher $\Delta{ }^{15} \mathrm{~N}$ rates that range from $2.79-$ $7.22 \%$ (Mill et al. 2007). We found no evidence of herbivore $\Delta{ }^{15} \mathrm{~N}$ varying with dietary

$274 \delta \delta^{15} \mathrm{~N}$. Instead, we used published $\Delta^{15} \mathrm{~N}$ estimates (Mill et al. 2007) to calculate a mean $\Delta{ }^{15} \mathrm{~N}$ of herbivorous reef fish (4.778\%), before calculating individual trophic position 276 with an additive approach (Equation 3) following Post (2002) and Hussey et al. (2014).

$$
T P_{\text {additive }}=T P_{\text {base }}+\frac{\delta^{15} N_{f i s h}-\delta^{15} N_{\text {base }}}{4.778}
$$

$278 \mathrm{TP}_{\text {base }}$ was set to 2 and $\delta^{15} \mathrm{~N}_{\text {base }}$ was the mean $\delta^{15} \mathrm{~N}$ of the smallest herbivore species

(Centropyge flavissima, $\delta^{15} \mathrm{~N}_{\text {base }}=12.21$, mass $\left.=6.5 \mathrm{~g}\right)$.

\section{Trophic position - body size analyses}


Though species level predator-prey mass ratios are generally positive (Brose et al.

282 2006), others have suggested that when ontogenetic niche shifts are prevalent, size structuring should operate most strongly at the individual level (Jennings et al. 2001). As

284 such, we conducted trophic position - body size analyses at the species level (i.e. 'crossspecies approach' sensu Jennings et al. 2001) and at the individual level to test the

286 hypothesis that coral reef food webs are size-structured, and if so, at what level of organization size structuring is evident.

288 Phylogenetic patterns in trophic position - body size relationships can result in non-independence of data points that can bias analyses of community structure (Jennings

290 et al. 2001; Romanuk et al. 2011). To account for this non-independence we used mixed models to fit random structures that accounted for variation shared between individuals of

292 the same species and/or family (detailed below). First, in the species-based analyses, we used linear mixed effects models to examine the relationship between the mean trophic

294 position of each species and the maximum observed $\log _{2}$ body mass of each species across the entire community, while accounting for phylogenetic relatedness of species

296 within families. Specifically, we fitted family as a random effect in order to account for non-independence of trophic position - body mass relationships within families, and then

298 used the Akaike Information Criterion for small sample sizes $\left(\mathrm{AIC}_{\mathrm{c}}\right)$ to select the optimum random effects structure (random slope or random intercept model) (Zuur et al.

300 2009). Second, in the individual-based analyses, we examined the relationship between the trophic position of individual fishes and their $\log _{2}$ body mass class. To account for the 302 non-independence of individual fishes within species, and species within families, we included both species and family as random effects in a linear mixed effects model and 
304 again used $\mathrm{AIC}_{\mathrm{c}}$ to select the optimum random effects structure. In both the species-based and the individual-based analysis, we tested for differences in slopes of trophic position

306 body mass relationships between our two putative trophic pathways, carnivores and herbivores, by assessing the significance of trophic pathway as an interaction term with

308 AICc (Burnham \& Anderson 2002). We measured the goodness-of-fit of the fixed covariates in each analysis by estimating the marginal $\mathrm{R}^{2}$ of each model (Nakagawa \&

310 Schielzeth 2012). Finally, we conducted sensitivity analyses to test the robustness of our results to different herbivore fractionation values $\left(\Delta^{15} \mathrm{~N}\right)$ and different sampling locations

312 (Supplementary Material). We note that there are multiple families included in each trophic pathway (Table 1). Thus, although no family contains individuals from both

314 trophic pathways, it seems likely that any observed differences in slopes can be attributed to true differences between herbivores and carnivores (as opposed to being conflated with 316 phylogeny).

All abundance $\sim$ body size and trophic position $\sim$ body size analyses were

318 performed in R (version 3.0.2; R Development Core Team 2013) using the packages MuMIn (Barton 2013) and nlme (Pinheiro et al. 2015). The R code used in our analyses 320 is available on Github (https://github.com/baumlab/Robinson-Baum_2016_CJFAS).

\section{Results}

\section{Abundance - body size relationships}

In total, 28831 individual fish from 163 species, ranging in body mass from 1.02 $\mathrm{g}$ to $23.04 \mathrm{~kg}$ were enumerated in our underwater visual censuses. Of these, 3602 were

326 herbivores from 44 species that ranged in size from $1.02 \mathrm{~g}$ to $5.87 \mathrm{~kg}$, and 25229 were 
carnivores from 119 species that ranged in size from $1.03 \mathrm{~g}$ to $23.04 \mathrm{~kg}$. Mean individual 328 size of the herbivore group (mean mass $=230.63 \mathrm{~g}, \mathrm{SE}=14.72$ ) was greater than the carnivore group (mean mass $=188.83 \mathrm{~g}, \mathrm{SE}=16.78$ ). These average sizes reflect the high

330 proportion of small planktivores in the carnivore group, rather than a disproportionate abundance of large herbivores. For example, for fishes above $20 \mathrm{~g}$, mean carnivore mass

332 was $488.74 \mathrm{~g}$ and mean herbivore mass was $401.89 \mathrm{~g}$.

When all individual fishes from the full reef fish community were considered

334 together, the size spectrum had a negative slope $(b=-1.580,95 \% \mathrm{CI}=-1.585,-1.576)$, indicating a strong decrease in abundance with increasing body size, consistent with size

336 structuring of community abundances. Size spectrum slopes were, however, distinct for herbivore and carnivore trophic pathways (Fig. 2), with the slope of the herbivore group

$338(b=-1.270,95 \% \mathrm{CI}=-1.281,-1.260)$ significantly shallower than that of the carnivore group $(b=-1.644,95 \% \mathrm{CI}=-1.649,-1.638)$. In the context of metabolic predictions, the

340 herbivore slope $(b=-1.270)$ is shallower than predicted for species within one trophic level $(\sim-1.75)$ and the carnivore slope $(b=-1.644)$ is shallower than predicted for species

342 across trophic levels ( -2) (modified from Brown \& Gillooly 2003; Reuman et al. 2008). We also examined the effect of sampling bias on $b$ by fitting spectra across different body

344 size ranges. We found that removing the largest individuals had a minimal effect on the $b$ estimate for carnivores but made the herbivore estimate shallower, while removing the 346 smallest individuals steepened the slope of both carnivores and herbivores considerably (Supplementary Material). For example, by only including fishes $>8 \mathrm{~g}$ in our analyses 348 our estimated size spectrum slopes for herbivores and carnivores were $b=-1.494$ and $b=$ -1.775 , respectively (Supplementary Material). Overall, across all body size ranges 
350 sampled as well as all other sensitivity analyses (i.e. across different years, divers, and sampling locations), the herbivore spectrum was always significantly shallower than the

352 carnivore spectrum and the slopes for herbivores and carnivores were always shallower than predicted by metabolic theory (Supplementary Material).

\section{Trophic position - body size relationships}

From twenty-three species within five functional groups, we sampled a total of

344 fish ranging in body size from $0.1 \mathrm{~g}$ to $6.35 \mathrm{~kg}$ (Table 1$)$. Of these, the trophic position of herbivores ranged from 1.76 to 2.62 , and that of carnivores ranged from 2.42

358 to 5.06. In the species-based analysis, trophic position increased significantly with maximum $\log _{2}$ body mass across all species (estimate $\left.=0.12, \mathrm{P}=0.002\right)($ Fig. 3a; Table

360 2). After aggregating individuals according to their trophic pathway, we found that the best model (as assessed by $\mathrm{AIC}_{\mathrm{c}}$ ) was the random intercept model with family as a

362 random effect (so accounting for similar trophic position - body mass relationships within families) and with trophic pathway (carnivore, herbivore) included as an interaction term

364 (Fig. 3b; Table 2). The relationship between trophic position and maximum $\log _{2}$ body mass was positive and significant (estimate $=0.114, \mathrm{P}=0.002$ ), but was not significantly

366 different between carnivores and herbivores (estimate $=-0.061, \mathrm{P}=0.636$; Table 2). This form of the model did, however, account for a much greater proportion of the variability

368 (Fig. 3b) than the model in which all species were aggregated (Fig. 3a). In the individualbased analysis, the trophic position of individual fishes also increased significantly with

370 their $\log _{2}$ body mass across the community, but with a shallower slope than in the species-based analysis (estimate $=0.067, \mathrm{P}<0.001)$ and with very little of the variability

372 explained (Fig. 3c). Once trophic pathways were included, as with the species-based 
analysis, the optimum individual-based model included the $\log _{2}$ body mass class*trophic

374 pathway interaction term and much more of the variability was explained: the slope of the relationship between trophic position - body size was positive and significant (estimate $=$

$3760.071, \mathrm{P}=0.004)$, but again was not significantly different between carnivores and herbivores (estimate $=0.004, \mathrm{P}=0.943)($ Fig. $3 \mathrm{~d}$, Table 2$)$. In both individual-based

378 models (i.e. with and without trophic pathways considered), $\mathrm{AIC}_{\mathrm{c}}$ supported a random slope and intercept structure with species nested within family as the random effect, thus

380 allowing trophic position - body mass relationships to vary between species and families (Supplementary Material). For both the species-based and individual-based models,

382 slopes were not distinct between herbivores and carnivores for any of the random effects structures that we fitted (random slopes or random intercepts, families and/or species).

384 We note that, in the individual-based models, had we not taken into account nonindependence between species and families we would have found significantly different

386 slopes between carnivores and herbivores (estimate $=-0.066, \mathrm{P}=0.022)$. We found no evidence that relationships were influenced by sampling location (north or south coast

388 sites) or our assumed herbivore fractionation value (Supplementary Material).

\section{Discussion}

Our analyses of visual census and stable isotope data provide solid quantitative

392 evidence that coral reef food webs are size structured. Abundance - body mass relationships were negative, indicating energetic constraints on community structure in

394 accordance with size-based theory (Trebilco et al. 2013). Trophic position - body mass relationships were significantly positive across species and across individuals, revealing 
396 strong size-based feeding in a diverse tropical food web. We also found differences in size spectra between carnivorous and herbivorous fish species that are consistent with

398 Brown \& Gillooly's (2003) prediction that body size scaling relationships reflect differences in energy acquisition between individuals sharing energy and individuals

400 competing across trophic levels.

\section{Abundance - body size relationships}

We found strong evidence that abundance scales negatively with body size in coral reef communities, for individuals spanning across four orders of magnitude in body

404 size. Our results align with ecological theory that energetic constraints cause abundance to scale negatively with body size (Brown \& Gillooly 2003; Jennings \& Mackinson 2003;

406 Trebilco et al. 2013) and, specifically, provide the first evidence that reef fish species competing across trophic levels (carnivores) have a steeper size spectrum than reef fish

408 species sharing energy within a trophic level (herbivores) (Brown \& Gillooly 2003). Previous analyses of size spectra on coral reefs, which were focused on examining how

410 size spectra change with fishing pressure rather than testing macroecological theory, examined data from moderately to highly degraded systems and sampled individuals

412 from a narrower range of body sizes ( 10-60 cm) (Dulvy et al. 2004; Graham et al. 2005; Wilson et al. 2010). These studies used binning-based methods and fitted size spectra

414 with body lengths rather than masses making direct comparisons to our results difficult. Our results are more directly comparable with Ackerman et al.'s (2004) census of reef

416 fish $>1 \mathrm{~g}$ that, once corrected for their binning-based slope estimate, yields a size spectrum slope of $b=-1.75 \pm 0.3495 \%$ confidence interval, which is steeper than our

418 estimate for the full community size spectrum slope $(b=-1.580)$ but still overlaps our 
95\% CI. Herein, we have also extended the size spectrum approach to show that the size

420 structuring of reef fish abundances is dependent on how energy is shared within the reef community, suggesting that the food web structure of a diverse tropical community is

422 governed by energetic constraints on size spectra that are similar to predictions for pelagic marine ecosystems (Brown \& Gillooly 2003; Blanchard et al. 2009).

Our size spectra estimates were, however, shallower than predictions from metabolic theory and size-based theory for body size scaling relationships (i.e. the

426 energetic equivalence hypothesis, and the trophic transfer correction) (Brown \& Gillooly 2003; Trebilco et al. 2013). Empirical tests of abundance - body size relationships may

428 deviate from theory when abundance estimates fail to account for every species that shares energy within the community (Maxwell \& Jennings 2006; Jennings et al. 2007).

430 Accurately quantifying the abundance of small cryptic fish species (Bozec et al. 2011), nocturnal fish species, and the invertebrate species that compete with small fishes

432 (Ackerman et al. 2004) is a challenge inherent to all UVC methods, including ours on Kiritimati. By underestimating the smallest individuals that contribute to energy flux in

434 the coral reef food web, size spectra slope estimates will be biased upwards. Indeed, we found that our estimated size spectra slopes steepened when we sequentially removed the

436 smallest size classes from the data set, suggesting that our underwater visual censuses had not quantified all of the smallest fishes in the community. Non-instantaneous UVC

438 methods also can overestimate or underestimate the abundance of large mobile fishes depending on fish behaviour (Ward-Paige et al. 2010; Bozec et al. 2011), and thus bias

440 spectra estimates upwards or downwards. However, given that large individuals are considerably lower in abundance than small individuals, and that in probabilistic spectra 
442 fitting methods each individual counted is treated equally, we expect that this bias would be quite small.

444 In addition to the potential bias introduced by underwater visual census methods, exploitation pressure can steepen the size spectrum by reducing the abundance of the

446 largest size classes (Blanchard et al. 2009). We attempted to reduce any potential influence of fishing pressure on trophic structure by sampling at minimally disturbed sites

448 on Kiritimati. However, slopes did become slightly shallower (from -1.644 and -1.270 to -1.553 and -1.223 for carnivores and herbivores, respectively) after excluding the four

450 sites nearest to Kiritimati's villages, consistent with predicted fishing effects on the size spectrum (Supplementary Material). Nevertheless, the pattern we observed that herbivore

452 size spectra were significantly shallower than carnivore size spectra was consistent across all sites and body size ranges (Supplementary Material), indicating that the influence of

454 fishing on our results is minimal.

\section{Trophic position - body size relationships}

456 We also found strong evidence that trophic position increases with body size in coral reef food webs. In contrast to previous stable isotope analyses in reef systems, our

458 results suggest that coral reef food webs are structured by size-based feeding relationships at both the species and individual level. For example, previous tests of

460 feeding relationships have reported positive, negative and non-significant relationships between $\delta^{15} \mathrm{~N}$ and body size within individual reef fish species (Greenwood et al. 2010).

462 However, a lack of statistical power can prevent detection of intra-specific shifts in $\delta^{15} \mathrm{~N}$ (Galvan et al. 2010). In the only previous comparison of feeding relationships across

464 multiple coral reef species that we are aware of, $\delta^{15} \mathrm{~N}$ - body length relationships were 
positive across five carnivorous species, consistent with the carnivore size structuring in 466 our results, but non-significant across four herbivorous species (de la Morinière et al. 2003). Our finding that the trophic position of herbivorous fish increased with body size 468 (from 1.76 to 2.62 ) was therefore unexpected. Enriched individual $\delta^{15} \mathrm{~N}$ may result from increased consumption of detritus and small benthic invertebrates by herbivorous

470 surgeonfish species (Acanthuridae) (Carassou et al. 2008; Dromard et al. 2015). We note that, in general, understanding of trophic fractionation in herbivorous fishes remains

472 limited (Mill et al. 2007) and assigning trophic positions to herbivorous reef fish is an area requiring further study. Nevertheless, our herbivore trophic position - body size

474 relationships are robust to varying $\Delta \mathrm{N}$ (Supplementary Material), indicating that the consumption of $\delta^{15} \mathrm{~N}$ enriched detritus and invertebrates may increase with herbivore 476 body size.

Despite evidence from gut content analyses that fish predators are generally larger 478 than their prey in temperate marine systems (Barnes et al. 2010), species-based tests of size structure using stable isotopes have produced equivocal results. For example,

480 Jennings et al.'s (2001) study found a positive trophic position - body size relationship for fishes in the Celtic Sea but a non-significant relationship for fishes in the North Sea. In a

482 tropical stream food web, despite gut content analysis revealing size-structured feeding relationships, isotope analysis of the full food web found no relationship between

484 predator size and trophic position (Layman et al. 2005). We caution that in size-structured communities, where an individual's ecological role is best defined by its size rather than

486 its species, species-based tests may obscure positive relationships between trophic position and body size that are evident at the individual level, if size is not controlled for 
488 in the study design. Here, because we sampled across the size range of each species we were able to detect positive trophic position - body size relationships at both the 490 individual and the species level.

Two additional factors that may have limited the ability of previous studies to 492 detect positive trophic position - body size relationships are variability in trophic fractionation values between trophic positions (Hussey et al. 2014) and confounding

494 effects of phylogeny (Romanuk et al. 2011). Romanuk et al. (2011), for example, highlighted the importance of considering evolutionary history in analyses of diverse

496 communities where, by accounting for the non-independence of species within orders, their analysis of a global dataset of fish species found that species-based trophic position

498 - body size relationships are positive. In contrast, if we had failed to include a random effects structure in our individual-based model, we would have identified a significant

500 difference between the trophic position - body mass relationships of carnivore and herbivores. Without appropriate consideration of potential errors in the conversion of

$502 \delta^{15} \mathrm{~N}$ to trophic positions and in the statistical treatment of phylogenetic relationships, examination of trophic structure from stable isotope analyses can be misleading.

\section{Trophic pathways on coral reefs}

We found that carnivores and herbivores were characterized by distinct abundance - body size relationships, though they had similar trophic position - body size

508 relationships. Only a few previous studies have examined the effect of metabolic constraints on abundance - body size relationships as we did here. Our results align well

510 with observations that the North Sea benthic community has a shallower spectrum than 
the pelagic community (Maxwell \& Jennings 2006, Blanchard et al. 2009). In the North

512 Sea, the detection of size spectra based on different modes of energy acquisition provided further insights into energy flux through the food web, where Blanchard et al. (2009)

514 examined how the energy-sharing community could be coupled to a steep predationbased community by large mobile predators to confer food web stability. Their model has

516 since been adapted to examine the coupling of size spectra between carnivore and herbivore groups in a Caribbean reef food web (Rogers et al. 2014). Though Rogers et al.

518 (2014) did not compare size spectrum slope estimates between groups, our analyses provide empirical support for distinct structuring of herbivore and carnivore groups. Beyond body size relationships, analysis of trophic pathways in other systems have used carbon isotope signatures to identify distinct energy sources and thus track

522 energy flux through food web compartments or 'channels' (Rooney et al. 2006). Though we did not have sufficient carbon samples for the reef fish we sampled on Kiritimati,

524 others have identified discrete benthic (Dromard et al. 2015) and pelagic (Wyatt et al. 2012) energy sources on coral reefs, and mixed benthic-pelagic diets of large predatory

526 fish species in these ecosystems (McCauley et al. 2012; Frisch et al. 2014). We suggest that our results provide a useful foundation for future examination of coupled food web

528 structure in coral reef systems. Notably, theoretical models and empirical analyses suggest that coupling by mobile consumers can foster food web stability (Rooney et al.

530 2006; Blanchard et al. 2009; Britten et al. 2014) and, given the widespread decline in top predator abundance on reefs (Williams et al. 2010; Nadon et al. 2012), it is critical that

532 we develop a greater understanding of how differences in energy utilization between trophic pathways may define the structure of coral reef food webs. 
534 We present novel evidence of size structuring in a minimally impacted diverse tropical food web, spanning 163 species across four orders of magnitude in body mass.

536 By combining visual census data with stable isotope analysis we were able to examine the scaling of body size with both abundance and trophic position. Differences in the size

538 spectra of carnivores and herbivores reflected energetic constraints on abundance - body size relationships between individuals sharing energy and those competing across trophic

540 levels, but did not tightly match theoretical predictions. Our analyses offer new perspectives on the structure of coral reef food webs, and we suggest that future studies

542 strive to further delineate community structure through the lens of body size distributions. Overall, size-based approaches hold great promise for integrating the complexities of

544 food webs into simple quantitative measures and elucidating fundamental properties of aquatic ecosystems.

\section{Acknowledgements}

The authors are deeply grateful to the Government of Kiribati for facilitating this research on Kiritimati, especially K. Teboko Tarau and P. Tofinga and our other collaborators at the Ministry of Fisheries and the Ministry of Environment, Lands and Agricultural Development. The authors also thank S. Clark and R. Trebilco for their

552 dedicated efforts collecting the field data; A. Burrill, J. Giddens, S. Walsh, M. Watson, and L. Wiwchar for additional field assistance; G. Aroella-Jarvie, A. Burrill, L. Coleman,

554 P. Duffy, J. McDevitt-Irwin, V. Pattison, C. Smith for their assistance processing stable isotope samples; M. Deith and J. Dunic for developing and managing the stable isotope

556 database; N. Dulvy and R. Trebilco for initial discussions about sampling design; and A. Edwards for discussions about fitting size spectra. The authors gratefully acknowledge 
558 support for this research from The Leverhulme Trust (JPWR), a Discovery Grant to JKB from the Natural Sciences and Engineering Research Council of Canada, Research

560 Fellowships to JKB from the Alfred P. Sloan Foundation and the Schmidt Ocean Institute, the Rufford Foundation (JKB), the Canadian Foundation for Innovation (JKB),

562 National Geographic (AB), and the University of Victoria. Finally, we thank Brian Shuter, Henrique Giacomini, and two anonymous reviewers for their helpful comments

564 that have substantially improved our manuscript.

\section{References}

Ackerman, J.L., Bellwood, D.R., and Brown, J.H. 2004. The contribution of small

568 individuals to density-body size relationships: examination of energetic equivalence in reef fishes. Oecologia 139: 568-571. doi:10.1007/s00442-004-1536-0.

570 Alvarez-Filip, L., Gill, J.A., and Dulvy, N.K. 2011. Complex reef architecture supports more small-bodied fishes and longer food chains on Caribbean reefs. Ecosphere 2: 117. doi:10.1890/ES11-00185.1.

Andersen, K.H., and Beyer, J.E. 2006. Asymptotic size determines species abundance in

574 the marine size spectrum. Am. Nat. 168: 54-61. doi:10.1086/504849.

Barnes, C., Maxwell, D., Reuman, D.C., and Jennings, S. 2010. Global patterns in

576 predator-prey size relationships reveal size dependency of trophic transfer efficiency. Ecology 91: 222-232.

578 Barton, K. 2013. MuMIn: Multi-model inference. R package version 1.9.13. http://CRAN.R-project.org/package=MuMIn

580 Bascompte, J., Melian, C., and Sala, E. 2005. Interaction strength combinations and the 
overfishing of a marine food web. Proceedings of the National Academy of Sciences

582 102: 5443-5447. doi:10.1073/pnas.0501562102.

Bell, J.D., Craik, G.J.S., Pollard, D.A., and Russell, B.C. 1985. Estimating length

584 frequency-distributions of large reef fish underwater. Coral Reefs 4: 41-44. doi:10.1007/BF00302203.

586 Blanchard, J.L., Jennings, S., Law, R., Castle, M.D., McCloghrie, P., Rochet, M.-J., and Benoit, E. 2009. How does abundance scale with body size in coupled size-structured food webs? J. Anim. Ecol. 78: 270-280. doi:10.1111/j.1365-2656.2008.01466.x.

Bozec, Y.-M., Kulbicki, M., Laloë, F., Mou-Tham, G., and Gascuel, D. 2011. Factors affecting the detection distances of reef fish: implications for visual counts. Mar. Biol. 158: 969-981. doi:10.1007/s00227-011-1623-9.

592 Britten, G.L., Dowd, M., Minto, C., Ferretti, F., and Boero, F. 2014. Predator decline leads to decreased stability in a coastal fish community. Ecol. Lett. 17: 1518-1525. doi10.1111/ele.12354.

Brose, U., Jonsson, T., Berlow, E.L., Warren, P., Banasek-Richter, C., Bersier, L.-F., 596 Blanchard, J.L., Brey, T., Carpenter, S.R., Blandenier, M.-F.C., Cushing, L., Dawah, H.A., Dell, T., Edwards, F., Harper-Smith, S., Jacob, U., Ledger, M.E., Martinez, 598 N.D., Memmott, J., Mintenbeck, K., Pinnegar, J.K., Rall, B.C., Rayner, T.S., Reuman, D.C., Ruess, L., Ulrich, W., Williams, R.J., Woodward, G., and Cohen, J.E. 600 2006. Consumer-resource body-size relationships in natural food webs. Ecology 87: 2411-2417. doi:10.1890/0012-9658(2006)87[2411:CBRINF]2.0.CO;2.

602 Brown, J.H., and Gillooly, J.F. 2003. Ecological food webs: high-quality data facilitate theoretical unification. Proc. Natl. Acad. Sci. U.S.A. 100: 1467-1468. 
604 doi:10.1073/pnas.0630310100.

Brown, J.H., Gillooly, J.F., Allen, A.P., Savage, V.M., and West, G.B. 2004. Toward a 606 metabolic theory of ecology. Ecology 85: 1771-1789. doi: 10.1890/03-9000.

Burnham, K.P., and Anderson, D.R. 2002. Model Selection and Multimodel Inference: A 608 Practical Information-Theoretic Approach. 2nd edition. Springer, New York.

Carassou, L., Kulbicki, M., Nicola, T.J.R., and Polunin, N.V.C. 2008. Assessment of fish 610 trophic status and relationships by stable isotope data in the coral reef lagoon of New Caledonia, southwest Pacific. Aquat. Living Resour. 21: 1-12. doi:

$612 \quad$ 10.1051/alr:2008017.

Caut, S., Angulo, E., and Courchamp, F. 2009. Variation in discrimination factors $(\Delta 15 \mathrm{~N}$ 614 and $\Delta 13 \mathrm{C}$ ): the effect of diet isotopic values and applications for diet reconstruction. J. Appl. Ecol. 46: 443-453. doi: 10.1111/j.1365-2664.2009.01620.x.

616 Choat, J.H. 1991. The Biology of Herbivorous Fishes on Coral Reefs. In The Ecology of Fishes on Coral Reefs. Edited by P.F. Sale. Academic Press, San Diego, California.

618 pp. $120-155$.

de la Morinière, E.C., Pollux, B., Nagelkerken, I., Hemminga, M.A., Huiskes, A., and

620 Van der Velde, G. 2003. Ontogenetic dietary changes of coral reef fishes in the mangrove-seagrass-reef continuum: stable isotope and gut-content analysis. Mar.

622 Ecol. Prog. Ser. 246: 279-289. doi:10.3354/meps246279.

Cohen, J.E., Jonsson, T., and Carpenter, S.R. 2003. Ecological community description 624 using the food web, species abundance, and body size. Proc. Natl. Acad. Sci. USA 100: 1781-1786. doi:10.1073/pnas.232715699.

626 Deith, M.D. 2014. Is an ecosystem driven by its species or their traits? Taxonomic and 
functional diversity in Pacific coral reef fish communities. Honours thesis,

628 Department of Biology, University of Victoria, Victoria, B.C.

Dromard, C.R., Bouchon-Navaro, Y., Harmelin-Vivien, M., and Bouchon, C. 2015.

630 Diversity of trophic niches among herbivorous fishes on a Caribbean reef

(Guadeloupe, Lesser Antilles), evidenced by stable isotope and gut content analyses .

632 J. Sea Res. 95: 124-131. doi:10.1016/j.seares.2014.07.014.

Dulvy, N.K., Polunin, N.V., Mill, A.C., and Graham, N.A. 2004. Size structural change

634 in lightly exploited coral reef fish communities: evidence for weak indirect effects.

Can. J. Fish. Aquat. Sci. 61: 466-475. doi:10.1139/f03-169.

636 Edwards, A.M. 2008. Using likelihood to test for Lévy flight search patterns and for general power-law distributions in nature. J. Anim. Ecol. 77: 1212-1222.

638 doi:10.1111/j.1365-2656.2008.01428.x.

Edwards, A.M., Freeman, M.P., Breed, G.A., and Jonsen, I.D. 2012. Incorrect Likelihood

640 Methods Were Used to Infer Scaling Laws of Marine Predator Search Behaviour. PLoS ONE 7: e45174. doi:10.1371/journal.pone.0045174.t001.

642 Elton, C. 1927. Animal Ecology. The Macmillan Company, New York.

Frisch, A.J., Ireland, M., and Baker, R. 2013. Trophic ecology of large predatory reef

644 fishes: energy pathways, trophic level, and implications for fisheries in a changing climate. Mar. Biol. 161: 61-73. doi:10.1007/s00227-013-2315-4.

646 Froese, R., and Pauly, D. 2014, November 20. FishBase.

Galván, D.E., Sweeting, C.J., and Reid, W. 2010. Power of stable isotope techniques to 648 detect size-based feeding in marine fishes. Mar. Ecol. Prog. Ser. 407: 271-278. doi:10.3354/meps08528. 
650 Graham, N., Dulvy, N.K., Jennings, S., and Polunin, N. 2005. Size-spectra as indicators of the effects of fishing on coral reef fish assemblages. Coral Reefs 24: 118-124. 652 doi:10.1007/s00338-004-0466-y.

Greenwood, N.D.W., Sweeting, C.J., and Polunin, N.V.C. 2010. Elucidating the 654 trophodynamics of four coral reef fishes of the Solomon Islands using $\delta 15 \mathrm{~N}$ and ס13C. Coral Reefs 29: 785-792. doi:10.1007/s00338-010-0626-1.

656 Hilting, A.K., Currin, C.A., and Kosaki, R.K. 2013. Evidence for benthic primary production support of an apex predator-dominated coral reef food web. Mar. Biol. 160: 1-15. doi:10.1007/s00227-013-2220-x.

Hussey, N.E., MacNeil, M.A., McMeans, B.C., Olin, J.A., Dudley, S.F.J., Cliff, G., 660 Wintner, S.P., Fennessy, S.T., and Fisk, A.T. 2014. Rescaling the trophic structure of marine food webs. Ecol. Lett. 17: 239-250. doi:10.1111/ele.12226.

662 Jennings, S., and Mackinson, S. 2003. Abundance-body mass relationships in sizestructured food webs. Ecol. Lett. 6: 971-974. doi:10.1046/j.1461-0248.2003.00529.x.

664 Jennings, S., De Oliveira, J.A.A., and Warr, K.J. 2007. Measurement of body size and abundance in tests of macroecological and food web theory. J. Anim. Ecol. 76: 7282. doi:10.1111/j.1365-2656.2006.01180.x.

Jennings, S., Pinnegar, J.K., Polunin, N.V.C., and Boon, T.W. 2001. Weak cross-species

668 relationships between body size and trophic level belie powerful size-based trophic structuring in fish communities. J. Anim. Ecol. 70: 934-944. doi:10.1046/j.0021$670 \quad$ 8790.2001.00552.x.

Kiribati National Statistics Office 2012. Kiribati 2010 Census Volume 1 \& 2. Secretariat 672 of the Pacific Community. Statistics for Development Programme, Noumea, New 
Caledonia.

674 Kulbicki, M., Guillemot, N., and Amand, M. 2005. A general approach to length-weight relationships for New Caledonian lagoon fishes. Cybium 29: 235-252.

676 Layman, C.A., Winemiller, K.O., Arrington, D.A., and Jepsen, D.B. 2005. Body size and trophic position in a diverse tropical food web. Ecology 86: 2530-2535.

678 Lindeman R.L. 1942. The trophic-dynamic aspect of ecology. Ecology 23: 399-417.

Maxwell, T.A.D., and Jennings, S. 2006. Predicting abundance-body size relationships in

680 functional and taxonomic subsets of food webs. Oecologia 151: 748-748. doi:10.1007/s00442-006-0624-8.

682 May, R.M. 1973. Qualitative stability in model ecosystems. Ecology 54: 638-641.

McCann, K.S., Rasmussen, J.B., and Umbanhowar, J. 2005. The dynamics of spatially

684 coupled food webs. Ecol. Lett. 8: 513-523. doi:10.1111/j.1461-0248.2005.00742.x.

McCauley, D.J., Young, H.S., Dunbar, R.B., Estes, J.A., Semmens, B.X., and Micheli, F.

686 2012. Assessing the effects of large mobile predators on ecosystem connectivity.

Ecol. Appl. 22: 1711-1717. doi:10.1890/11-1653.1.

688 Mill, A.C., Pinnegar, J.K., and Polunin, N.V.C. 2007. Explaining isotope trophic-step fractionation: why herbivorous fish are different. Funct. Ecol. 21: 1137-1145.

690 doi:10.1111/j.1365-2435.2007.01330.x.

Mittelbach, G.G., and Persson, L. 1998. The ontogenetic niche and species interactions in

692 size-structured populations. Can. J. Fish. Aquat. Sci. 55: 1454-1465. doi:10.1139/cjfas-2013-0558.

694 Nadon, M.O., Baum, J.K., Williams, I.D., McPherson, J.M., Zgliczynski, B.J., Richards, B.L., Schroeder, R.E., and Brainard, R.E. 2012. Re-Creating Missing Population 
696 Baselines for Pacific Reef Sharks. Conserv. Biol. 26: 493-503. doi:10.1111/j.15231739.2012.01835.x.

698 Nakagawa, S., and Schielzeth, H. 2012. A general and simple method for obtaining R2 from generalized linear mixed-effects models. Methods Ecol. Evol. 4: 133-142. doi: 10.1111/j.2041-210x.2012.00261.x

Peters, R.H. 1983. The Ecological Implications of Body Size. Cambridge University Press, Cambridge.

Pinheiro J, Bates D, DebRoy S, Sarkar D and R Core Team 2015. nlme: Linear and Nonlinear Mixed Effects Models. R package version 3.1-120.

Plass-Johnson, J.G., McQuaid, C.D., and Hill, J.M. 2012. Stable isotope analysis indicates a lack of inter- and intra-specific dietary redundancy among ecologically important coral reef fishes. Coral Reefs 32: 429-440. doi:10.1007/s00338-012-09887.

Post, D.M. 2002. Using stable isotopes to estimate trophic position: models, methods, and $710 \quad$ assumptions. Ecology 83: 703-718.

R Development Core Team (2013) R: A language and environment for statistical 712 computing. R Foundation for Statistical Computing, Vienna, Austria. Available from http://www.R-project.org/.

714 Reuman, D.C., Mulder, C., Raffaelli, D., and Cohen, J.E. 2008. Three allometric relations of population density to body mass: theoretical integration and empirical tests in 149

716 food webs. Ecol. Lett. 11: 1216-1228. doi:10.1111/j.1461-0248.2008.01236.x.

Rogers, A., Blanchard, J.L., and Mumby, P.J. 2014. Vulnerability of Coral Reef Fisheries to a Loss of Structural Complexity. Curr. Biol. 24: 1000-1005. 
doi:10.1016/j.cub.2014.03.026.

720 Romanuk, T.N., Hayward, A., and Hutchings, J.A. 2011. Trophic level scales positively with body size in fishes. Global Ecol. Biogeogr. 20: 231-240. doi:10.1111/j.14668238.2010.00579.x.

Rooney, N., and McCann, K.S. 2012. Integrating food web diversity, structure and stability. Trends Ecol. Evol. 27: 40-46. doi:10.1016/j.tree.2011.09.001.

Rooney, N., McCann, K., Gellner, G., and Moore, J.C. 2006. Structural asymmetry and 726 the stability of diverse food webs. Nature 442: 265-269. doi:10.1038/nature04887.

Rooney, N., McCann, K.S., and Moore, J.C. 2008. A landscape theory for food web architecture. Ecol. Lett. 11: 867-881. doi:10.1111/j.1461-0248.2008.01193.x.

Sandin, S.A., Smith, J.E., DeMartini, E.E., Dinsdale, E.A., Donner, S.D., Friedlander, A.M., Konotchick, T., Malay, M., Maragos, J.E., Obura, D., Pantos, O., Paulay, G., Richie, M., Rohwer, F., Schroeder, R.E., Walsh, S., Jackson, J.B.C., Knowlton, N., and Sala, E. 2008. Baselines and Degradation of Coral Reefs in the Northern Line Islands. PLoS ONE 3. doi: 10.1371/journal.pone.0001548.

734 Trebilco, R., Baum, J.K., Salomon, A.K., and Dulvy, N.K. 2013. Ecosystem ecology: size-based constraints on the pyramids of life. Trends Ecol. Evol. 28: 423-431. doi:10.1016/j.tree.2013.03.008.

Tunney, T.D., McCann, K.S., Lester, N.P., and Shuter, B.J. 2012. Food web expansion and contraction in response to changing environmental conditions. Nat. Commun. 3: 1105. doi:10.1038/ncomms2098.

740 Vander Zanden, M., and Rasmussen, J.B. 2001. Variation in $\delta 15 \mathrm{~N}$ and $\delta 13 \mathrm{C}$ trophic fractionation: implications for aquatic food web studies. Limnol. and Oceanogr. 46: 

2061-2066. doi:10.4319/1o.2001.46.8.2061.

Walsh, S.M. 2011. Ecosystem-scale effects of nutrients and fishing on coral reefs. J. Mar. Biol. 2011: 1-13. doi:10.1007/BF00000006.

Ward-Paige, C., Flemming, J.M., and Lotze, H.K. 2010. Overestimating fish counts by non-instantaneous visual censuses: consequences for population and community descriptions. PLoS ONE 5: e11722. doi:10.1371/journal.pone.0011722.

White, E.P., Enquist, B.J., and Green, J.L. 2008. On estimating the exponent of powerlaw frequency distributions. Ecology 89: 905-912. doi:10.1890/07-1288.1.

750 Williams, I.D., Richards, B.L., Sandin, S.A., Baum, J.K., Schroeder, R.E., Nadon, M.O., Zgliczynski, B., Craig, P., McIlwain, J.L., and Brainard, R.E. 2010. Differences in reef fish assemblages between populated and remote reefs spanning multiple archipelagos across the central and western Pacific. J. Mar. Biol. 2011. doi: $10.1155 / 2011 / 826234$.

Wilson, S.K., Fisher, R., Pratchett, M.S., Graham, N.A.J., Dulvy, N.K., Turner, R.A., 756 Cakakaka, A., and Polunin, N.V.C. 2010. Habitat degradation and fishing effects on the size structure of coral reef fish communities. Ecol Appl 20: 442-451. doi:10.1890/08-2205.1.

Wyatt, A.S.J., Waite, A.M., and Humphries, S. 2012. Stable isotope analysis reveals community-level variation in fish trophodynamics across a fringing coral reef. Coral Reefs 31: 1029-1044. doi:10.1007/s00338-012-0923-y.

762 Zuur, A.F., Ieno, E.N., Walker, N.J., Saveliev, A.A., and Smith, G.M. 2009. Mixed effects models and extensions in ecology with R. Springer Science, New York. 
Table 1. Body sizes, $\delta^{15} \mathrm{~N}$ values, and sample sizes $(N)$ for the twenty-three fish species

766 sampled on Kiritimati for the stable isotope analyses, with each species assigned an trophic pathway (carnivore or herbivore) based on their functional group (FG: BI =

768 benthic invertivore, $\mathrm{Pi}=$ piscivore, $\mathrm{ZP}=$ zooplanktivore, $\mathrm{De}=$ detritivore, $\mathrm{He}=$ herbivore). 


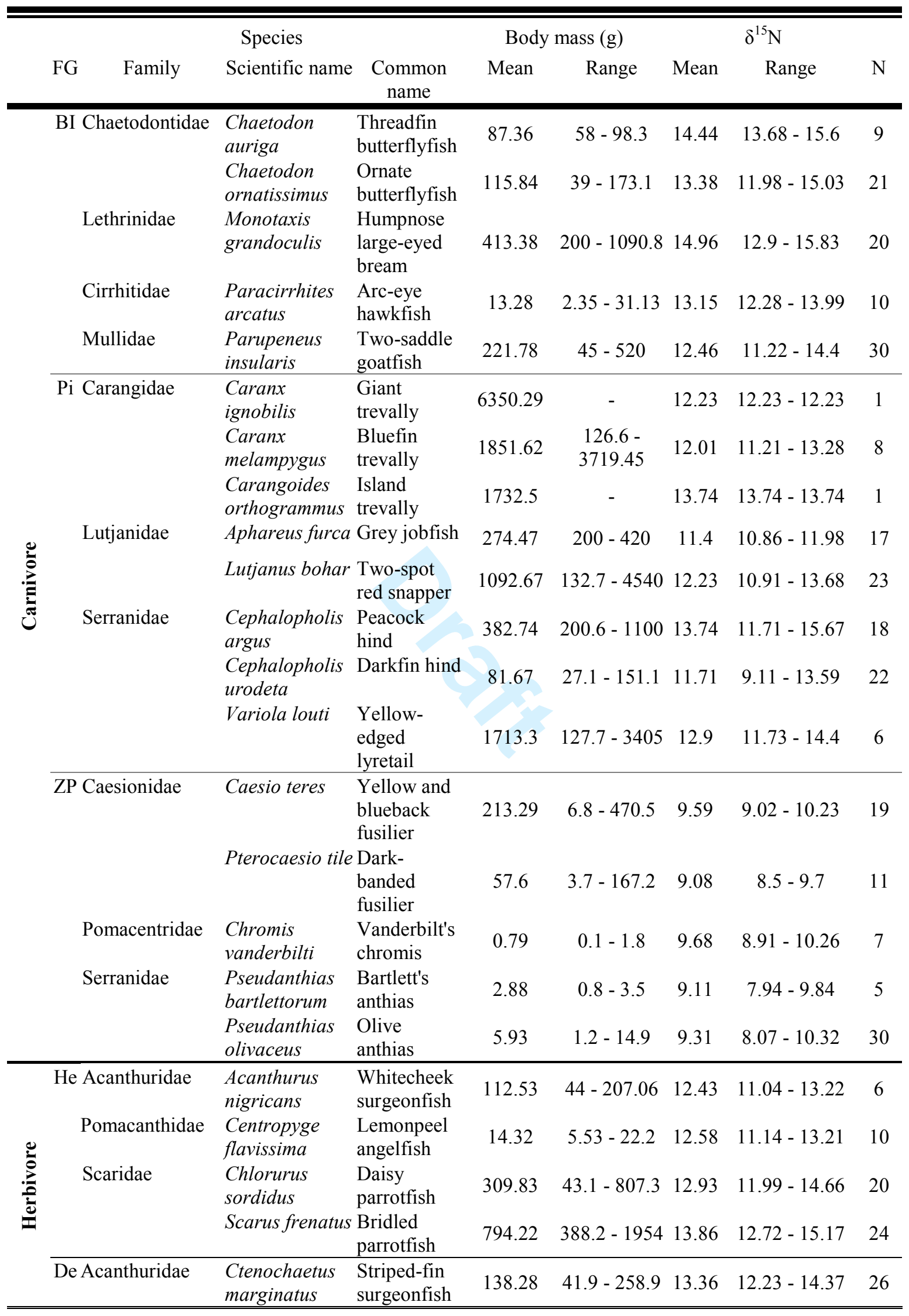


770 Table 2. Parameter estimates of the best model (as evaluated by $\mathrm{AIC}_{\mathrm{c}}$ ) for trophic position - $\log _{2}$ body mass relationships in the species-based (linear mixed effects model

772 with family as a random effect) and individual-based (linear mixed effects model with species nested within family as a random effect) analyses.

\begin{tabular}{|c|c|c|c|c|c|c|}
\hline & Coefficient & Estimate & $\begin{array}{c}\text { Standard } \\
\text { error }\end{array}$ & $P$ value & $\underset{\mathrm{R}^{2}}{\text { Marginal }}$ & $\Delta \mathrm{AIC}_{\mathrm{c}}$ \\
\hline \multirow{2}{*}{ Species-based } & Intercept & 2.33 & 0.328 & $<0.001$ & \multirow{2}{*}{0.17} & \multirow{2}{*}{5.45} \\
\hline & $\log _{2}$ mass & 0.12 & 0.029 & 0.002 & & \\
\hline \multirow{4}{*}{$\begin{array}{c}\text { Species-based with trophic } \\
\text { pathway }\end{array}$} & Intercept & 2.73 & 0.282 & $<0.001$ & \multirow{4}{*}{0.62} & \multirow{4}{*}{0} \\
\hline & Intercept (herbivore) & -0.978 & 1.018 & 0.359 & & \\
\hline & $\log _{2}$ mass & 0.114 & 0.028 & 0.003 & & \\
\hline & $\log _{2}$ mass*herbivore & -0.061 & 0.124 & 0.636 & & \\
\hline \multirow{2}{*}{ Individual-based } & Intercept & 2.76 & 0.242 & $<0.001$ & \multirow{2}{*}{0.04} & \multirow{2}{*}{8.8} \\
\hline & $\log _{2}$ mass & 0.067 & 0.02 & $<0.001$ & & \\
\hline \multirow{4}{*}{$\begin{array}{l}\text { Individual-based with } \\
\text { trophic pathway }\end{array}$} & Intercept & 3.09 & 0.186 & $<0.001$ & \multirow{4}{*}{0.45} & \multirow{4}{*}{0} \\
\hline & Intercept (herbivore) & -1.45 & 0.398 & 0.004 & & \\
\hline & $\log _{2}$ mass & 0.071 & 0.024 & 0.005 & & \\
\hline & $\log _{2}$ mass $*$ herbivore & 0.004 & 0.052 & 0.943 & & \\
\hline
\end{tabular}

774 
776 Fig. 1. Study sites on Kiritimati, Line Islands, Republic of Kiribati. All sites have minimal fishing pressure and are located on the north and east coast of the atoll, which is

778 outside of the upwelling zone on the leeward (lagoon facing) side. Fish specimens were collected at 10 sites in July-Aug of 2011 and 2012 (triangles). Underwater visual

780 censuses were carried out at 14 sites in the summers of 2011 and/or 2013 (denoted by circles and triangles). Villages are marked with red circles that are scaled to their

782 population sizes.

Fig. 2. Size spectra (i.e. abundance - body size relationships) of the coral reef fish

784 community. Left: Rank-frequency plot of reef fish body masses for carnivores (blue, $\mathrm{n}=$ 25344 fish) and herbivores (green, $\mathrm{n}=3628$ fish). Individual body masses are plotted as

786 points and overlaid with the fitted size spectrum (i.e. bounded power law distribution). Right: size spectra slopes (b) with 95\% confidence intervals for carnivores (blue) and 788 herbivores (green).

Fig. 3. Trophic level - body size relationships a, b: Species-based analyses. Linear mixed

790 effects models of trophic position and $\log _{2}$ body mass $(\mathrm{g})$ in the coral reef fish community (a) across all species $(n=23),(b)$ for the two trophic pathways, carnivores (blue, $n=18$

792 species) and herbivores (green, $\mathrm{n}=5$ species). For each species, the mean trophic position and $95 \%$ confidence intervals are plotted against its maximum mass. c, d: Individual-

794 based analyses. Linear mixed effects models individual trophic position and of individual $\log _{2}$ body mass $(\mathrm{g})$ in the coral reef fish community (c) across all individuals $(\mathrm{n}=344)$

796 and (d) for the two trophic pathways, carnivores (blue, $\mathrm{n}=258$ ) and herbivores (green, $\mathrm{n}$ =86). Individual trophic position estimates are plotted against body mass class (with 
798 jitter, transparent colour), and overlaid with mean trophic position (solid colour) of each body mass class. 


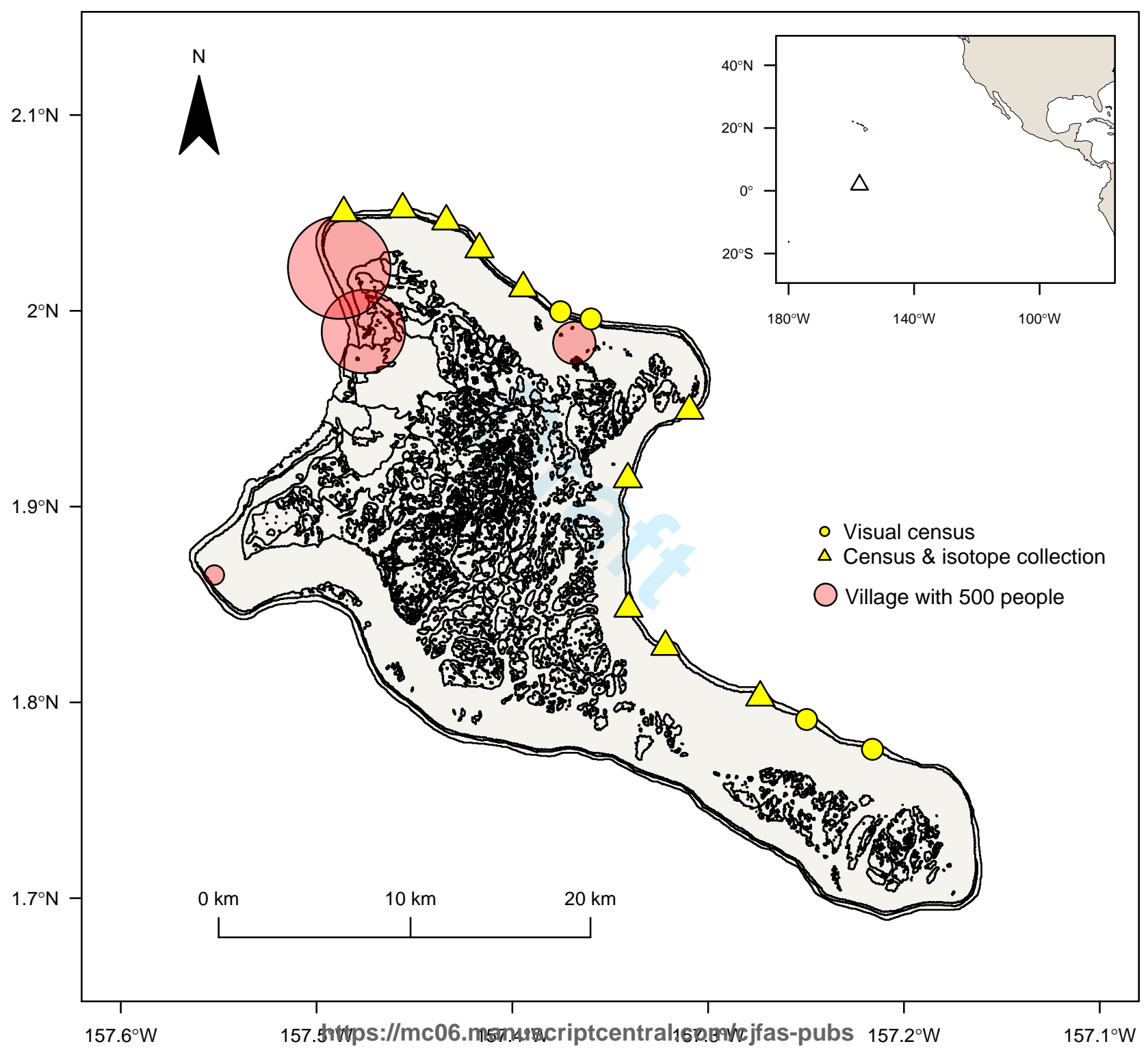




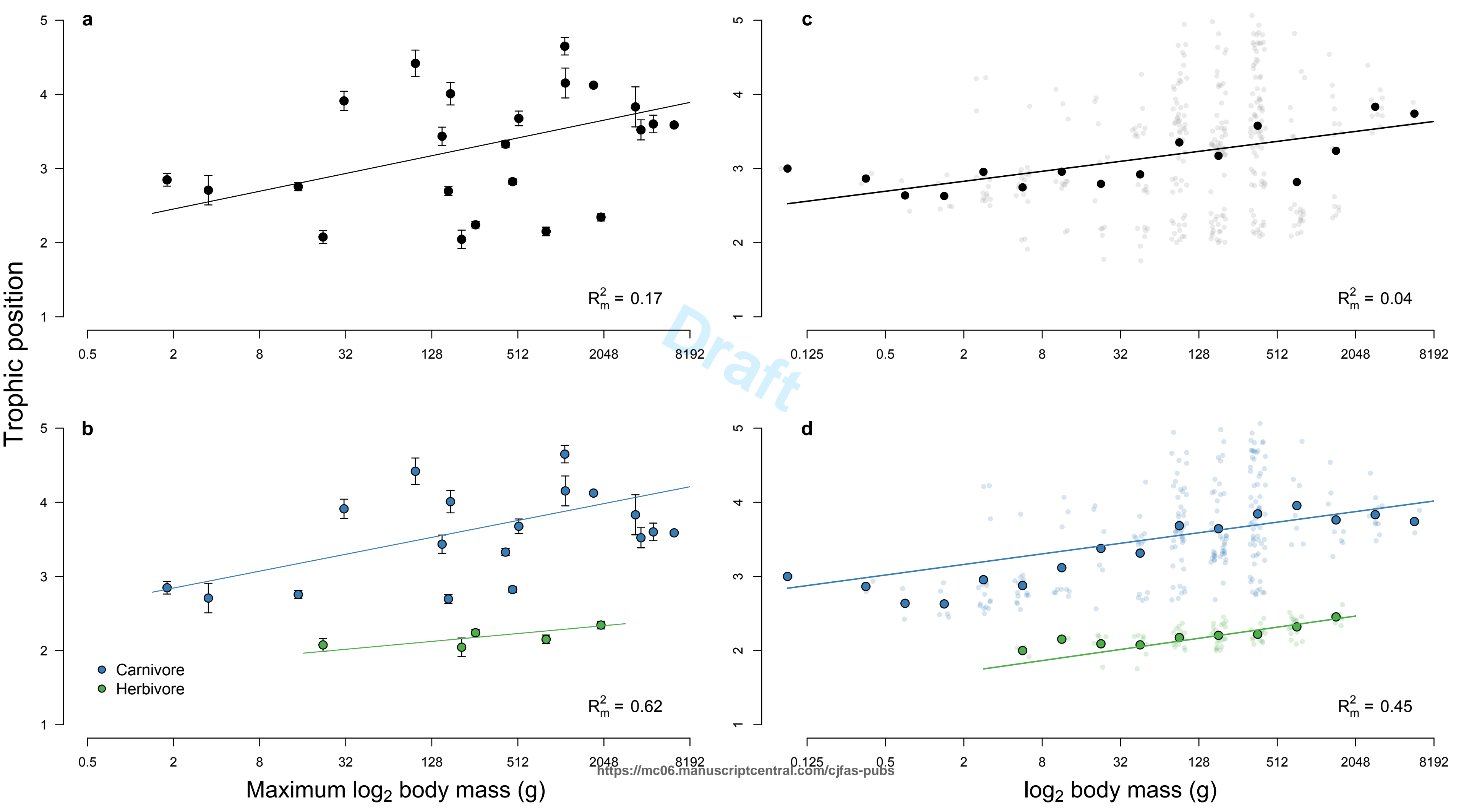

